\title{
Pleural effusions associated with squamous cell lung carcinoma have a low diagnostic yield and a poor prognosis
}

\author{
Michael Dorry ${ }^{1}$, Kevin Davidson ${ }^{2}$, Rajesh Dash ${ }^{3}$, Rachel Jug ${ }^{3}$, Jeffrey M. Clarke ${ }^{4}$, Andrew B. Nixon ${ }^{5}$, \\ Kamran Mahmood $^{1 \wedge}$ \\ ${ }^{1}$ Division of Pulmonary, Allergy and Critical Care Medicine, Department of Medicine, Duke University, Durham, NC, USA; ${ }^{2}$ Department of \\ Medicine, WakeMed Hospital, Raleigh, NC, USA; ${ }^{3}$ Department of Pathology, Duke University, Durham, NC, USA; ${ }^{4}$ Division of Thoracic \\ Oncology, Department of Medicine, Duke University, Durham, NC, USA; ${ }^{5}$ Duke Cancer Institute, Durham, NC, USA \\ Contributions: (I) Conception and design: All authors; (II) Administrative support: K Mahmood; (III) Provision of study materials or patients: \\ K Mahmood, R Dash, R Jug; (IV) Collection and assembly of data: K Mahmood, M Dorry, K Davidson, R Dash, R Jug; (V) Data analysis and \\ interpretation: K Mahmood, M Dorry, K Davidson, R Dash, R Jug, JM Clarke, AB Nixon; (VI) Manuscript writing: All authors; (VII) Final approval \\ of manuscript: All authors. \\ Correspondence to: Kamran Mahmood, MD, MPH. Department of Medicine, Division of Pulmonary, Allergy and Critical Care Medicine, Duke \\ University, DUMC 102356, Durham, NC 27710, USA. Email: K.mahmood@duke.edu.
}

Background: Malignant pleural effusion (MPE) portends a poor prognosis in non-small cell lung cancer (NSCLC). However, the yield of pleural fluid cytology as well as survival of patients with MPE associated with squamous cell carcinoma versus adenocarcinoma is not well understood. We conducted this study to assess the diagnostic yield of pleural cytology and survival of patients with NSCLC related MPE.

Methods: We performed a single-center, retrospective analysis of patients with NSCLC related MPE between 2010 and 2017. Kaplan-Meier method was used to compare survival and Cox proportional hazards analysis to assess if squamous cell cytopathology was associated with mortality.

Results: We identified 277 patients, 29 with squamous cell and 248 with adenocarcinoma MPE. Pleural fluid cytology from initial thoracentesis was diagnostic in $13.8 \%(4 / 29)$ patients with squamous cell and $80.2 \%(199 / 248)$ with adenocarcinoma $(\mathrm{P}<0.001)$. Cytology from second thoracentesis was diagnostic in $13.3 \%$ (2/15) patients with squamous cell carcinoma, compared to $37.5 \%$ (12/32) with adenocarcinoma $(\mathrm{P}=0.17)$. There was no statistically significant difference in the pleural biopsy yield from medical pleuroscopy or video-assisted thoracoscopic surgery (VATS) in the two groups. The median survival of patients with squamous cell MPE was 112 [interquartile range (IQR): 44-220] days versus 194 (IQR: 54-523) days in adenocarcinoma (Log-rank test $\mathrm{P}=0.04$ ). Multivariate Cox proportional hazards analysis showed that squamous cell cytopathology was independent predictor of mortality (hazard ratio for death of $1.73,95 \% \mathrm{CI}$ : 1.1-2.6; $\mathrm{P}=0.01)$.

Conclusions: Pleural fluid cytology has a low diagnostic yield in squamous cell carcinoma MPE, and these patients have a poor survival compared to lung adenocarcinoma.

Keywords: Malignant pleural effusion (MPE); squamous cell lung carcinoma; non-small cell lung cancer (NSCLC); diagnostic yield; prognosis

Submitted Feb 16, 2021. Accepted for publication Apr 22, 2021.

doi: $10.21037 /$ tlcr-21-123

View this article at: http://dx.doi.org/10.21037/tlcr-21-123

^ ORCID: 0000-0002-8643-2634. 


\section{Introduction}

Malignant pleural effusions (MPEs) are estimated to occur with an incidence greater than 150,000 cases per year in the United States (1). MPE is seen in about $15 \%$ patients with non-small cell lung carcinoma (NSCLC) and portends a poor prognosis (2). Classified as stage IVA, median survival of lung cancer patients with MPE is four months, which is lower than malignant effusions metastatic from other primary sites $(3,4)$.

Thoracentesis is generally the first procedure performed when MPE is suspected (5-7). The procedure is safe, well tolerated and can diagnose and stage patients with suspected lung cancer. The yield of initial thoracentesis for diagnosis of malignancy is about $65 \%$, and subsequent thoracentesis increases the yield by $25 \%(5,6,8,9)$. After non-diagnostic thoracentesis, pleural biopsy is usually performed via medical pleuroscopy, video-assisted thoracoscopic surgery (VATS) or image guidance $(10,11)$. There is limited literature on the diagnostic yield of cytology followed by pleural biopsy in patients with NSCLC related pleural effusions (12). In addition, the prognosis of patients with subtypes of NSCLC with pleural effusions has not been compared. We performed a retrospective analysis of the patients with NSCLC related pleural effusions to assess the diagnostic yield of cytology and pleural biopsy and determine the prognostic variables associated with survival. We present the following article in accordance with the REMARK reporting checklist (available at http://dx.doi. org/10.21037/tlcr-21-123).

\section{Methods}

We performed a retrospective review of NSCLC patients with confirmed or suspected MPE. Confirmed MPE was defined as either positive pleural fluid cytology or pleural biopsy confirming malignancy. Suspected MPE was defined as sterile, exudative pleural effusion in a patient with known lung cancer when clinicians did not pursue pleural biopsy. Patients were identified by review of cytology and pathology database as well as review of patients referred to the interventional pulmonology service for thoracentesis, indwelling pleural catheter (IPC) placement, or pleuroscopy between January $1^{\text {st }}, 2010$ and December $31^{\text {st }}, 2017$. We excluded all cases of MPE that were not due to NSCLC. Patient information including age, gender, race, history of smoking, pleural fluid characteristics, cytology of pleural fluid, pathology reports of pleural biopsies, and survival data were collected. The study was conducted in accordance with the Declaration of Helsinki (as revised in 2013). The study was approved by institutional review board of Duke University (Pro00091556) and individual consent for this retrospective analysis was waived.

\section{Cyto-pathological examination of pleural fuid and pleural biopsies}

The cell blocks were prepared from pleural fluid using $95 \%$ alcohol or a mixture of pooled plasmin and thrombin to congeal cellular material. A pellet was generated by centrifuging $15 \mathrm{~mL}$ of pleural fluid at 2,800 rpm. The pellet was re-suspended in Cytolyt (Hologic, Marlborough, MA, USA), centrifuged again, and supernatant was discarded. Drops of $95 \%$ alcohol or plasma-thrombin were added until the cellular sediment clotted. The clot was fixed in $10 \%$ neutral buffered formalin for routine histologic processing. If the pellet had insufficient cellularity, more cell blocks could be requested by the pathologist using additional volumes of sample. For most patients, only one pellet was used for cytological analysis. Pleural biopsy specimens were submitted entirely for fixation in $10 \%$ neutral buffered formalin followed by routine histologic processing, paraffin embedding, cutting of standard 5 micron thick sections, and staining with hematoxylin and eosin.

Cytologic features used to diagnose adenocarcinoma included single or small clusters of cells with enlarged nuclei, cytoplasmic vacuoles, and occasional signet ring cell morphology, as shown in Figure 1 (13). The cytomorphology of squamous cell carcinoma was characterized by dense cytoplasm, distinct cell borders, and occasional keratinization. Adenocarcinoma and squamous cell carcinoma were also distinguished using immunohistochemical (IHC) stains (13). Adenocarcinoma cells stained positively with thyroid transcription factor (TTF1), napsin A, monoclonal carcinoembryonic antigen (CEA), and cytokeratin (CK)-7. In contrast, squamous cell carcinoma stained positively with CK5/6, p40, and p63. IHC stains on pleural fluid specimens were also used to distinguish between adenocarcinoma and mesothelial cells where such confirmation was deemed helpful for the diagnosis. Immunoreactivity with epithelial cell adhesion molecule (EPCAM; also known as MOC-31 or Ber-EP4) and B72.3, and negative staining with Wilms' tumor (WT)1, calretinin, and podoplanin (D2-40) were used to support a diagnosis of adenocarcinoma. 


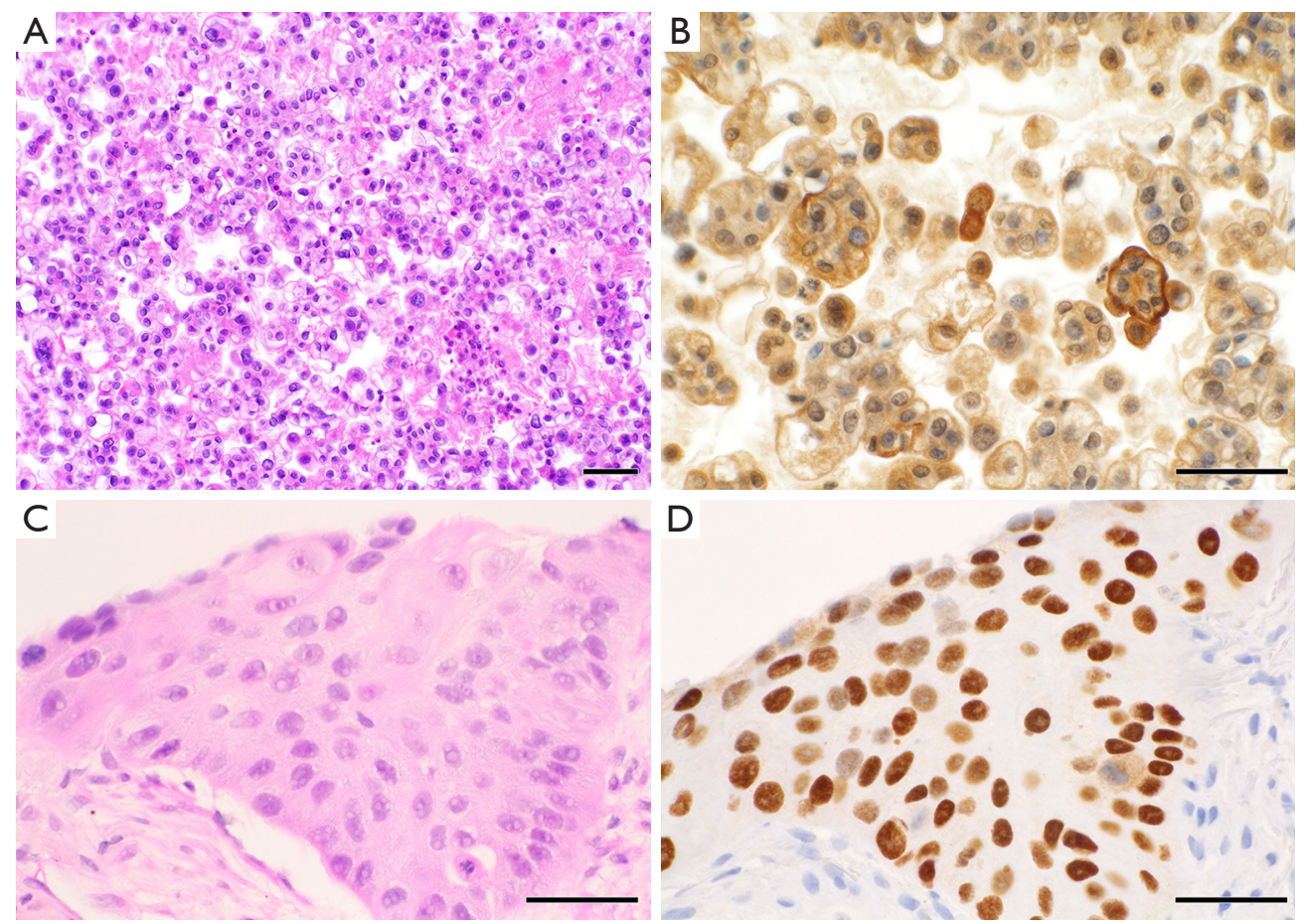

Figure 1 Representative malignant pleural effusion cytological examination: (A) adenocarcinoma hematoxylin \& eosin (H\&E), 20x. (B) Adenocarcinoma H\&E in cell block stained with CK7 immunohistochemical stain, 40x. (C) Squamous cell carcinoma in cell block stained with H\&E, 40x. (D) Squamous cell carcinoma with p63 immunohistochemical stain, 40×. Scale bar $=50 \mu \mathrm{m}$.

\section{Statistical analyses}

Descriptive statistics were used to summarize demographic and clinical characteristics of the patients. Continuous variables with normal distribution were described using mean and standard deviation (SD), while continuous variables with non-normal distribution were described as median and interquartile range (IQR). Categorical variables were summarized using percentage. Student's $t$-test was used to compare continuous variables and chi-square or Fisher's exact tests were used to compare categorical variables. To compare the survival of patients with squamous cell carcinoma and adenocarcinoma related MPE, a Kaplan-Meier survival curve was generated and the logrank test was used. Multivariable regression analysis using Cox proportional hazards model was performed to assess the variables associated with survival. For univariate and multivariate regression analysis, we chose clinically relevant variables that could impact survival of patients with MPEs including cytology/histology, age, gender, race, smoking status, indwelling pleural catheter (IPC), chemotherapy, immunotherapy, and tyrosine kinase inhibitor (TKI) therapy. Patients with missing data were excluded from the regression analysis. Adenocarcinoma cytology/histology was used as reference. Age was used as continuous variable. Race was used as a stratified variable with four categories (Caucasian, African American, Asian and Hispanic); Caucasian race was used as reference. A two-sided $\mathrm{P}$ value of 0.05 or less was considered to be statistically significant. Stata/SE 16.0 (StataCorp, College Station, TX, USA) was used for statistical analysis.

\section{Results}

We identified 277 cases of NSCLC related MPE who underwent pleural fluid drainage or other pleural procedures. There were 29 patients with squamous cell carcinoma and 248 patients with adenocarcinoma related MPE. Demographics of the patients are shown in Table 1. The diagnostic yield of pleural fluid cytology from initial thoracentesis in the cohort was $73.2 \%$ (203/277). But, the pleural cytology from initial thoracentesis was diagnostic in only $13.8 \%$ (4/29) of MPE in squamous cell carcinoma group, as compared to $80.2 \%(199 / 248)$ in adenocarcinoma group $(\mathrm{P}<0.001$, Table 2$)$. Second 
Table 1 Demographics of patients

\begin{tabular}{|c|c|c|c|}
\hline Demographics & $\begin{array}{l}\text { Squamous cell carcinoma pleural effusion } \\
\qquad(\mathrm{N}=29)\end{array}$ & $\begin{array}{l}\text { Adenocarcinoma pleural effusion } \\
\qquad(\mathrm{N}=248)\end{array}$ & $P$ value for difference \\
\hline Mean age $\pm S D$, years & $69.75 \pm 11.2$ & $68.54 \pm 10.5$ & 0.56 \\
\hline \multicolumn{4}{|l|}{ Gender, n (\%) } \\
\hline Male & $20(69.0)$ & $123(49.5)$ & 0.05 \\
\hline \multicolumn{4}{|l|}{ Race, n (\%) } \\
\hline Caucasian & $24(82.8)$ & $188(75.8)$ & $<0.01$ \\
\hline African American & $4(13.8)$ & $52(21.0)$ & \\
\hline Asian & $1(3.4)$ & $6(2.4)$ & \\
\hline Never smoker & $5(17.2)$ & $60(24.2)$ & \\
\hline Unknown & 0 & $2(0.8)$ & \\
\hline
\end{tabular}

Table 2 Diagnosis and management of patients

\begin{tabular}{|c|c|c|c|}
\hline Patient characteristics & $\begin{array}{l}\text { Squamous cell carcinoma } \\
\text { pleural effusion }(\mathrm{N}=29)\end{array}$ & $\begin{array}{l}\text { Adenocarcinoma pleural effusion } \\
\qquad(\mathrm{N}=248)\end{array}$ & $\begin{array}{l}\mathrm{P} \text { value for } \\
\text { difference }\end{array}$ \\
\hline Diagnosis of malignancy on thoracentesis $1, \%(x / n)$ & $13.8 \%(4 / 29)$ & $80.2 \%(199 / 248)$ & $<0.001$ \\
\hline \multicolumn{4}{|c|}{ Diagnosis of malignancy on pleural biopsy via medical pleuroscopy, \% (x/n) } \\
\hline \multicolumn{4}{|l|}{ Diagnosis of malignancy on pleural biopsy via VATS, \% (x/n) } \\
\hline Malignancy & $100 \%(3 / 3)$ & $93.3 \%(14 / 15)$ & 1.0 \\
\hline Fibropleuritis & 0 & $6.7 \%(1 / 15)$ & \\
\hline Pleural fluid exudative, $\%(x / n)$ & 5 unknown & 87 unknown & \\
\hline $\mathrm{LDH}(\mathrm{U} / \mathrm{L})$, mean $\pm \mathrm{SD}$ & $634.2 \pm 1,170$ & $459.1 \pm 638$ & 0.30 \\
\hline Protein $(\mathrm{g} / \mathrm{dL})$, mean $\pm \mathrm{SD}$ & $3.8 \pm 0.5$ & $3.9 \pm 0.8$ & 0.71 \\
\hline Amount drained $(\mathrm{mL})$, mean $\pm \mathrm{SD}$ & $849.6 \pm 508.9$ & $1,032.2 \pm 548.5$ & 0.19 \\
\hline IPC placement, \% (x/n) & $27.5 \%(8 / 29)$ & $53.6 \%(133 / 248)$ & 0.008 \\
\hline Survival since thoracentesis 1 , median days (IQR) & $112(44-220)$ & $194(54-523)$ & 0.02 \\
\hline
\end{tabular}

*, atypical cells seen on pleural biopsy via medical pleuroscopy in one patient with squamous cell carcinoma. IPC, indwelling pleural catheter; SD, standard deviation; IQR, interquartile range. 


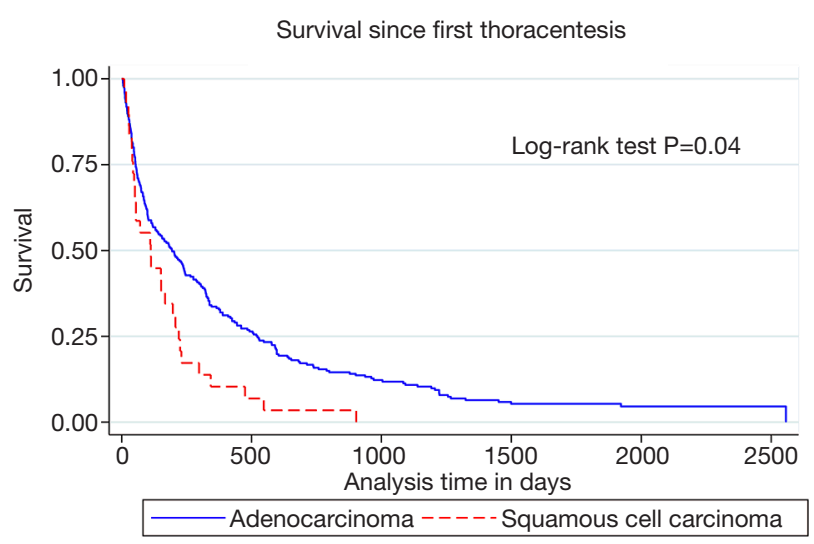

Figure 2 Survival curve of patients with malignant pleural effusion related to squamous cell lung carcinoma as compared to lung adenocarcinoma.

thoracentesis was performed for undiagnosed effusions in 15 patients with squamous cell carcinoma and 32 patients with adenocarcinoma. The diagnostic yield of second thoracentesis pleural fluid cytology was $13.3 \%(2 / 15)$ for squamous cell carcinoma, as compared to $37.5 \%$ (12/32) for adenocarcinoma $(\mathrm{P}=0.17)$. There was no difference in the volume of fluid drained or chemical characteristics between the two groups.

Medical pleuroscopy using semi-rigid pleuroscope (LTF160, Olympus USA, Center Valley, PA, USA) was performed to assess malignancy in some patients with undiagnosed pleural effusions or for chemical pleurodesis. In patients with squamous cell lung carcinoma, pleural biopsy with medical pleuroscopy was positive for malignancy in $50 \%$ (2/4), showed fibropleuritis in 25\% (1/4) and atypical cells in $25 \%(1 / 4)$ patients. In comparison in patients with adenocarcinoma, pleural biopsy with medical pleuroscopy showed malignancy in $66.6 \%(8 / 12)$ and fibropleuritis in $33.3 \%(4 / 12)$ of patients $(\mathrm{P}=0.6)$. Pleural biopsy with VATS was positive for malignancy in all 3 patients with squamous cell carcinoma; VATS pleural biopsy was positive for malignancy in $93 \%(14 / 15)$, and it showed fibropleuritis in $6.7 \%(1 / 15)$ of adenocarcinoma patients $(\mathrm{P}=1.0)$. This group of VATS patients included 3 patients who initially had negative pleuroscopy, but subsequently underwent VATS because of high clinical suspicion of malignancy. In these patients, VATS was diagnostic of malignancy in one patient with squamous cell carcinoma, and one out of two patients with adenocarcinoma. Only one patient in the adenocarcinoma group underwent CT guided transthoracic needle pleural biopsy which was positive.
IPC was placed in $27.5 \%$ of patients with squamous cell carcinoma and $53.6 \%$ of patients with adenocarcinoma MPE $(\mathrm{P}=0.007)$. In the adenocarcinoma group, cytology from pleural fluid was tested for molecular markers to assess for targetable genetic mutations in 81 patients, and it was adequate in $67(82.7 \%)$ patients. The patients with inadequate pleural fluid and others $(\mathrm{N}=136)$ had molecular markers tested on other specimens including bronchoscopic (57/136), pleuroscopic (8/136), surgical (48/136), CTguided transthoracic needle aspirate $(21 / 136)$ and blood (2/136). There was no difference in radiological features in squamous cell patients with positive or negative pleural cytology, as detailed in Table S1.

Median survival after first thoracentesis was 112 (IQR: 44-220) days in squamous cell carcinoma versus 194 (IQR: 54-523) days in adenocarcinoma MPE patients $(\mathrm{P}=0.02)$. Kaplan-Meier survival curves of squamous cell carcinoma compared to adenocarcinoma associated MPE were different, with log-rank test $\mathrm{P}$ value of 0.04 , as shown in Figure 2. Multivariate analysis (Table 3) showed that squamous cell cancer MPE was associated with a hazard ratio (HR) for death of 1.73, 95\% CI: 1.1-2.6 ( $\mathrm{P}=0.01)$. HR for death associated with tyrosine kinase inhibitors (TKIs) was 0.55 , 95\% CI: $0.39-0.79(\mathrm{P}=0.001)$. The survival of patients with positive pleural cytology was worse compared to the patients with negative cytology. HR for death with positive pleural cytology was $1.71,95 \%$ CI: $1.24-2.36$, $(\mathrm{P}=0.001)$ with Kaplan-Meier curves showing worse survival (log-rank test $\mathrm{P}$ value $=0.0009)$, as shown in Figure 3 .

\section{Discussion}

This is the first study to evaluate the comprehensive diagnostic work up and prognostic predictors in NSCLC patients with MPE. It demonstrated that the diagnostic sensitivity of pleural fluid cytology in NSCLC patients was lower for squamous cell carcinoma as compared to adenocarcinoma. In addition, squamous cell cytopathology was an independent predictor of mortality.

Porcel and colleagues reported an overall sensitivity of pleural fluid cytology obtained by thoracentesis in a cohort of MPE of different etiologies to be $51 \%$ with an increase to $59 \%$ on subsequent thoracentesis (6). However, the yield differed based on the type of malignancy and they found that the yield of pleural cytology was $78 \%$ in lung adenocarcinoma and $25 \%$ in squamous cell lung carcinoma. A study by Arnold et al. found an overall diagnostic yield of thoracentesis of $46 \%$ in MPE; the yield of lung 
Table 3 Predictors of survival in non-small cell lung cancer patients with pleural effusions

\begin{tabular}{|c|c|c|c|c|}
\hline Variables & \multicolumn{2}{|l|}{ Univariate analysis } & \multicolumn{2}{|c|}{ Multivariate analysis } \\
\hline Cytology/histology-Squamous & $1.7(1.2-2.6)$ & 0.004 & $1.73(1.1-2.6)$ & 0.01 \\
\hline Age & $0.99(0.9-1.0)$ & 0.5 & $0.99(0.9-1.0)$ & 0.23 \\
\hline Gender, male & $1.24(0.9-1.5)$ & 0.08 & $1.19(0.9-1.5)$ & 0.19 \\
\hline Smoker & $1.52(1.1-2.0)$ & 0.003 & $1.22(0.9-1.7)$ & 0.20 \\
\hline IPC & $1.28(1.0-1.6)$ & 0.05 & $1.48(1.1-1.9)$ & 0.004 \\
\hline Chemotherapy & $0.94(0.7-1.2)$ & 0.63 & $0.83(0.6-1.1)$ & 0.16 \\
\hline Immunotherapy & $0.83(0.5-1.2)$ & 0.42 & $0.65(0.4-1.0)$ & 0.06 \\
\hline
\end{tabular}

IPC, indwelling pleural catheter; TKI, tyrosine kinase inhibitor.

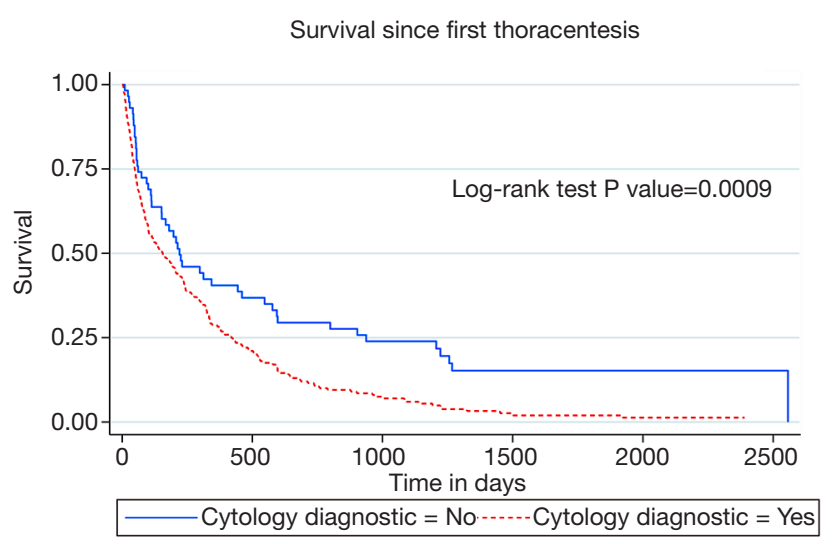

Figure 3 Survival curve of non-small cell lung cancer patients and malignant pleural effusion with diagnostic versus non-diagnostic pleural fluid cytology.

adenocarcinoma effusions was $82 \%$ and squamous cell lung carcinoma was $14 \%$ (14). Our findings are aligned with these studies as the yield of pleural fluid cytology in our cohort was $80.2 \%$ in adenocarcinoma and $13.8 \%$ with squamous cell lung carcinoma. The higher total yield of $73.2 \%$ of initial thoracentesis in our cohort, compared to the contemporary literature, is related to a high number of adenocarcinoma patients in this cohort. Similar results are reported by Grosu and colleagues (12). We have shown that such a difference in the thoracentesis yield with different tumor types persists even with subsequent thoracentesis. In addition, we showed that pleural biopsy with medical pleuroscopy or VATS increases the diagnostic yield in patients with negative pleural fluid cytology. Given these findings, in patients with known or suspected NSCLC, especially squamous cell carcinoma, if the pleural cytology from thoracentesis is negative, pleural biopsy with medical pleuroscopy or VATS should be considered.

In our study, pleuroscopy showed malignancy in $50 \%$ of patients with squamous cell carcinoma and $66 \%$ of patients with adenocarcinoma. VATS diagnosed malignancy in $100 \%$ of patients with squamous cell carcinoma and $93 \%$ of patients with adenocarcinoma. Only three patients with negative pleuroscopy underwent VATS for further confirmation, and two of these patients were diagnosed with malignancy. These results are similar to reported literature $(15,16)$.

Several possible reasons may be speculated for such a discrepancy in diagnostic sensitivity of pleural fluid cytology between squamous cell and adenocarcinoma. Squamous carcinoma cells have tight intercellular junctions and more robust anchors to the underlying basement membrane (17). This may lead to decreased shedding of squamous cells in pleural effusions as compared to bronchogenic adenocarcinomas. In addition, squamous cell carcinomas are more airway-centric, whereas adenocarcinomas are generally more peripheral in location which may allow easier spread to pleura (17). Some other malignancies, such as malignant mesothelioma, offer similar challenges to diagnosis based on pleural fluid cytology as squamous cell lung carcinoma $(18,19)$.

Another important finding of the study was that the survival of patients with squamous cell cancer related 
pleural effusions was worse compared to those with adenocarcinoma. Squamous cytopathology was associated with poor prognosis, even when controlled for variables like age, gender, smoking status, and different therapies, including TKI. These findings are consistent with the literature which shows that squamous cell carcinoma of the lung has a worse prognosis compared to lung adenocarcinoma $(2,20)$. In a study from Surveillance Epidemiology and End Results (SEER) registry including 57,685 patients with NSCLC, adenocarcinoma histology was associated with a better survival with multivariate HR of 0.92 (95\% CI: $0.88-0.96, \mathrm{P}<0.01$ ) compared to squamous histology (2). In more contemporary large randomized controlled studies involving frontline immunotherapy regimens, overall survival for squamous cell carcinoma patients was lower than non-squamous carcinoma patients despite routine use of immune checkpoint agents $(21,22)$. In an effort to develop prognostic score for MPE, LENT score has been proposed which takes into account LDH, ECOG performance score, neutrophil to lymphocyte ratio and tumor type, with lung cancer considered to be associated with worst prognosis (3). However, in LENT score, distinction was not made between adenocarcinoma and squamous cell cancer. In another study evaluating the pleuroscopy experience in $149 \mathrm{MPE}$ patients, a score (SELECT) for prognosis was suggested, including EGFR mutation and tumor type (23). Lung cancer was grouped in the high-risk category, without the differentiation of subtypes, and targetable mutations other than EGFR were not accounted for. Our study extended the current literature and specifically looked at the survival of MPE related to subtypes of NSCLC and highlighted the worse prognosis associated with squamous cell carcinoma pathology. In agreement with contemporary literature, we also showed that the patients with positive pleural cytology had a worse prognosis compared to patients with negative cytology (4). Consistent with the available literature $(24,25)$, TKI were associated with a better survival and were used for patients with MPE due to adenocarcinoma with targetable mutations. It is unclear whether the difference seen in survival of squamous cell carcinoma $v s$. adenocarcinoma is due to the difference in available therapies or other factors. These findings need to be investigated in larger prospective studies.

Strengths of our study include a large patient cohort with MPE related to NSCLC which demonstrates the yield of multiple thoracentesis and pleural biopsies, and highlights the low diagnostic yield of pleural cytology in squamous cell cancer MPE. We showed that patients with squamous cell lung carcinoma have a worse survival compared to patients with lung adenocarcinoma related MPE. Our study is limited by its retrospective, single center design and a small number of patients with squamous cell lung carcinoma. We cannot rule out if certain patients with negative thoracentesis were non-diagnostic or true negative, as not all patients underwent pleural biopsies. Future prospective studies at other centers are warranted to confirm our observations.

\section{Conclusions}

The yield of pleural fluid cytology for diagnosis of metastatic squamous cell lung cancer is low compared to adenocarcinoma. If clinically warranted, patients with undiagnosed pleural effusions related to NSCLC, especially squamous cell carcinoma, should undergo pleural biopsies to confirm malignancy. In addition, squamous cell pathology is an independent predictor of mortality. Effective therapies for squamous cell cancer should be explored, and the information about poor survival can help with future planning for the patients.

\section{Acknowledgments}

We acknowledge the strength and perseverance of our patients and their families with lung cancer, and the service of all the healthcare providers. We are also grateful to Steven R. Conlon, Senior Medical Photographer and Photography Course Director, Department of Pathology, Duke University, for acquiring and providing the microscopic images shown in Figure 1.

Funding: None.

\section{Footnote}

Reporting Checklist: The authors have completed the REMARK reporting checklist. Available at http://dx.doi. org/10.21037/tlcr-21-123

Data Sharing Statement: Available at http://dx.doi. org/10.21037/tlcr-21-123

Conflicts of Interest: All authors have completed the ICMJE uniform disclosure form (available at http://dx.doi. org/10.21037/tlcr-21-123). The authors have no conflicts of interest to declare. 
Ethical Statement: The authors are accountable for all aspects of the work in ensuring that questions related to the accuracy or integrity of any part of the work are appropriately investigated and resolved. The study was conducted in accordance with the Declaration of Helsinki (as revised in 2013). The study was approved by institutional review board of Duke University (Pro00091556) and individual consent for this retrospective analysis was waived.

Open Access Statement: This is an Open Access article distributed in accordance with the Creative Commons Attribution-NonCommercial-NoDerivs 4.0 International License (CC BY-NC-ND 4.0), which permits the noncommercial replication and distribution of the article with the strict proviso that no changes or edits are made and the original work is properly cited (including links to both the formal publication through the relevant DOI and the license). See: https://creativecommons.org/licenses/by-ncnd $/ 4.0 \%$.

\section{References}

1. American Thoracic S. Management of malignant pleural effusions. Am J Respir Crit Care Med 2000;162:1987-2001.

2. Morgensztern D, Waqar S, Subramanian J, et al. Prognostic impact of malignant pleural effusion at presentation in patients with metastatic non-small-cell lung cancer. J Thorac Oncol 2012;7:1485-9.

3. Clive AO, Kahan BC, Hooper CE, et al. Predicting survival in malignant pleural effusion: development and validation of the LENT prognostic score. Thorax 2014;69:1098-104.

4. Zamboni MM, da Silva CT Jr, Baretta R, et al. Important prognostic factors for survival in patients with malignant pleural effusion. BMC Pulm Med 2015;15:29.

5. Hooper C, Lee YC, Maskell N, et al. Investigation of a unilateral pleural effusion in adults: British Thoracic Society Pleural Disease Guideline 2010. Thorax 2010;65 Suppl 2:ii4-17.

6. Porcel JM, Esquerda A, Vives M, et al. Etiology of pleural effusions: analysis of more than 3,000 consecutive thoracenteses. Arch Bronconeumol 2014;50:161-5.

7. Asciak R, Rahman NM. Malignant Pleural Effusion: From Diagnostics to Therapeutics. Clin Chest Med 2018;39:181-93.

8. Garcia LW, Ducatman BS, Wang HH. The value of multiple fluid specimens in the cytological diagnosis of malignancy. Mod Pathol 1994;7:665-8.

9. Kaul V, McCracken DJ, Rahman NM, et al. Contemporary Approach to the Diagnosis of Malignant Pleural Effusion. Ann Am Thorac Soc 2019;16:1099-106.

10. Murthy V, Bessich JL. Medical thoracoscopy and its evolving role in the diagnosis and treatment of pleural disease. J Thorac Dis 2017;9:S1011-21.

11. Benamore RE, Scott K, Richards CJ, et al. Image-guided pleural biopsy: diagnostic yield and complications. Clin Radiol 2006;61:700-5.

12. Grosu HB, Kazzaz F, Vakil E, et al. Sensitivity of Initial Thoracentesis for Malignant Pleural Effusion Stratified by Tumor Type in Patients with Strong Evidence of Metastatic Disease. Respiration 2018;96:363-9.

13. Inamura K. Update on Immunohistochemistry for the Diagnosis of Lung Cancer. Cancers (Basel) 2018;10:72.

14. Arnold DT, De Fonseka D, Perry S, et al. Investigating unilateral pleural effusions: the role of cytology. Eur Respir J 2018;52:1801254.

15. Rahman NM, Ali NJ, Brown G, et al. Local anaesthetic thoracoscopy: British Thoracic Society Pleural Disease Guideline 2010. Thorax 2010;65 Suppl 2:ii54-60.

16. McDonald CM, Pierre C, de Perrot M, et al. Efficacy and Cost of Awake Thoracoscopy and Video-Assisted Thoracoscopic Surgery in the Undiagnosed Pleural Effusion. Ann Thorac Surg 2018;106:361-7.

17. Bonastre E, Brambilla E, Sanchez-Cespedes M. Cell adhesion and polarity in squamous cell carcinoma of the lung. J Pathol 2016;238:606-16.

18. Renshaw AA, Dean BR, Antman KH, et al. The role of cytologic evaluation of pleural fluid in the diagnosis of malignant mesothelioma. Chest 1997;111:106-9.

19. Dejmek A. Methods to improve the diagnostic accuracy of malignant mesothelioma. Respir Med 1996;90:191-9.

20. Wang BY, Huang JY, Chen HC, et al. The comparison between adenocarcinoma and squamous cell carcinoma in lung cancer patients. J Cancer Res Clin Oncol 2020;146:43-52.

21. Gandhi L, Rodriguez-Abreu D, Gadgeel S, et al. Pembrolizumab plus Chemotherapy in Metastatic Non-Small-Cell Lung Cancer. N Engl J Med 2018;378:2078-92.

22. Paz-Ares L, Luft A, Vicente D, et al. Pembrolizumab plus Chemotherapy for Squamous Non-Small-Cell Lung Cancer. N Engl J Med 2018;379:2040-51.

23. Quek JC, Tan QL, Allen JC, et al. Malignant pleural 
effusion survival prognostication in an Asian population. Respirology 2020;25:1283-91.

24. Yang J, Lee OJ, Son SM, et al. EGFR Mutation Status in Lung Adenocarcinoma-Associated Malignant Pleural Effusion and Efficacy of EGFR Tyrosine Kinase Inhibitors.
Cancer Res Treat 2018;50:908-16.

25. Wu SG, Yu CJ, Tsai MF, et al. Survival of lung adenocarcinoma patients with malignant pleural effusion. Eur Respir J 2013;41:1409-18.

Cite this article as: Dorry M, Davidson K, Dash R, Jug R, Clarke JM, Nixon AB, Mahmood K. Pleural effusions associated with squamous cell lung carcinoma have a low diagnostic yield and a poor prognosis. Transl Lung Cancer Res 2021;10(6):2500-2508. doi: 10.21037/tlcr-21-123 


\section{Supplementary}

Table S1 Radiological Characteristics of Squamous Lung Carcinoma Patients with Malignant Pleural Effusions

\begin{tabular}{|c|c|c|c|}
\hline CT or PET Scan Radiological Features & $\begin{array}{c}\text { Squamous Cell Pleural Cytology } \\
\text { Negative }(\mathrm{N}=23)\end{array}$ & $\begin{array}{c}\text { Squamous Cell Pleural Cytology } \\
\text { Positive }(\mathrm{N}=6)\end{array}$ & $\begin{array}{l}\text { P value for } \\
\text { difference* }\end{array}$ \\
\hline Size of effusion, ${ }^{\star \star}$ median (IQR) & $25(25-50)$ & $25(25-25)$ & 0.48 \\
\hline Size of largest mass/nodule, $\mathrm{cm}$, median (IQR) & $4(0.75-5)$ & $4.6(4-6.2)$ & 0.86 \\
\hline Location of mass/nodule $\mathrm{n}(\%)$ & & & 0.76 \\
\hline Central $2 / 3^{\text {rd }}$ & $8(34.7 \%)$ & $1(16.6 \%)$ & \\
\hline No mass/nodule & $2(8.7 \%)$ & 0 & \\
\hline Mediastinal lymphadenopathy present, n (\%) & $16(69.5 \%)$ & $6(100 \%)$ & 0.28 \\
\hline
\end{tabular}

${ }^{*}$ P-value for difference between continuous or categorical variables using $t$-test or Fisher's Exact Test, respectively. ${ }^{* *}$ Size of effusion, as percentage of hemithorax occupied on upright, posteroanterior chest X-ray. 